\title{
Do Automatic Self-Associations Relate to Suicidal Ideation?
}

\author{
Klaske A. Glashouwer • Peter J. de Jong • \\ Brenda W. J. H. Penninx • Ad J. F. M. Kerkhof • \\ Richard van Dyck $\cdot$ Johan Ormel
}

Published online: 20 August 2009

(C) The Author(s) 2009. This article is published with open access at Springerlink.com

\begin{abstract}
Dysfunctional self-schemas are assumed to play an important role in suicidal ideation. According to recent information-processing models, it is important to differentiate between 'explicit' beliefs and automatic associations. Explicit beliefs stem from the weighting of propositions and their corresponding 'truth' values, while automatic associations reflect more simple associations in memory. Both types of associations are assumed to have different functional properties and both may be involved in suicidal ideation. Thus far, studies into self-schemas and suicidal ideation focused on the more explicit, consciously accessible traces of self-schemas and predominantly relied on self-report questionnaires or interviews. To complement these 'explicit' findings and more directly tap into self-schemas, this study investigated automatic
\end{abstract}

\footnotetext{
K. A. Glashouwer $(\bowtie) \cdot$ P. J. de Jong

Department of Clinical Psychology,

University of Groningen,

Grote Kruisstraat 2/1

9712 TS Groningen, The Netherlands

e-mail: k.a.glashouwer@rug.nl
}

B. W. J. H. Penninx $\cdot$ R. van Dyck

Department of Psychiatry/EMGO Institute/Institute

for Neurosciences, VU University Medical Centre,

Amsterdam, The Netherlands

B. W. J. H. Penninx

Department of Psychiatry, Leiden University Medical Centre,

Leiden, The Netherlands

B. W. J. H. Penninx $\cdot$ J. Ormel

Department of Psychiatry, University Medical Centre Groningen,

University of Groningen,

Groningen, The Netherlands

\section{A. J. F. M. Kerkhof}

Department of Clinical and Health Psychology, VU University, Amsterdam, The Netherlands self-associations in a large scale community sample that was part of the Netherlands Study of Depression and Anxiety (NESDA). The results showed that automatic self-associations of depression and anxiety were indeed significantly related to suicidal ideation and past suicide attempt. Moreover, the interactions between automatic self-depressive (anxious) associations and explicit self-depressive (anxious) beliefs explained additional variance over and above explicit selfbeliefs. Together these results provide an initial insight into one explanation of why suicidal patients might report difficulties in preventing and managing suicidal thoughts.

Keywords Suicidal ideation - Automatic associations . Implicit Association Test · Self-schemas

Every year, nearly 1 million people over the world commit suicide (World Health Organization 2003). With this, suicide is at the top of the list of the ten leading causes of mortality and disease burden (DALYs) in adults between 15 and 59 years of age. One important risk factor associated with suicide is suicidal ideation (e.g., Kessler et al. 1999). Considering the potentially severe outcomes of suicidal ideation, it seems paramount to enhance insight into the underlying processes that may influence suicidal thoughts.

According to cognitive theories, psychopathological symptoms (including suicidal ideation) are the result of dysfunctional schemas that exist in memory (e.g., Beck and Steward 1989, cited in Weishaar and Beck 1992; Clark et al. 1999; Ellis 2006). Schemas are assumed to be more or less enduring cognitive structures that organize people's thoughts, feelings, and behaviors into stable patterns. It has been argued that individuals can have several different schemas, and that it is possible to switch between them (e.g., Young 1990). Dysfunctional self-schemas could lead 
to negative beliefs with respect to 'the self' which in turn may lead to suicidal thoughts. In line with this, several studies already showed that negative self-beliefs were related to suicide risk (e.g., Becker and Grilo 2007; Cox et al. 2004; Kienhorst et al. 1990; Lewinsohn et al. 1994), and suicidal ideation (e.g., Beck and Steward 1989, cited in Weishaar and Beck 1992; De Man and Gutiérrez 2002; Evans et al. 2004).

Thus far, studies into self-schemas and suicidal ideation focused on the more explicit, consciously accessible traces of self-schemas and predominantly relied on self-report questionnaires or interviews. However, recent informationprocessing models propose that it is important to differentiate between this explicit belief level and more automatic memory associations (e.g., Beevers 2005; Fazio and Towles-Schwen 1999; Wilson et al. 2000). Explicit beliefs are thought to reflect the outcome of the weighting of propositions and their corresponding "truth" values (i.e., validation processes; e.g., Gawronski and Bodenhausen 2006). In contrast, automatic self-associations are assumed to more directly mirror the activation of simple links in memory between 'self' and particular concepts (Gawronski and Bodenhausen 2006) and likewise may reflect a deeper level of cognitive structure more closely linked to the schemas themselves. The measurement of automatic self-associations is based on behavior (e.g., performance in reaction-time tasks), and therefore is believed to be less distorted by lack of introspection, social desirability or other demand characteristics (De Houwer 2002; Greenwald and Farnham 2000). Thus, while self-report measures are thought to capture explicit, conscious self-beliefs that stem from certain selfschemas, performance-based measures are assumed to more directly tap into the self-schemas.

Recent studies have already demonstrated a relationship between disorder-specific automatic self-associations and various types of psychopathological symptoms, such as symptoms of obsessive compulsive personality disorder (Weertman et al. 2008), chronic pain (Grumm et al. 2008), anxiety (Egloff and Schmukle 2002; Gamer et al. 2008; Glashouwer and de Jong, in press) and depression (Glashouwer and de Jong, in press). Most important for the present context, these automatic self-associations showed differential predictive validity for more spontaneous, uncontrollable kinds of behaviors such as autonomic responding and nonverbal behaviors (e.g., Asendorpf et al. 2002; Egloff and Schmukle 2002). Based on these findings, it has been argued that automatic associations may well play an important role in guiding relatively spontaneous, uncontrollable behaviors that are critically involved in psychopathology (e.g., Huijding and de Jong 2006), and may thus at least partially account for the persistence of psychopathological symptoms.

Building on this, we hypothesized that dysfunctional automatic self-associations might also contribute to the onset and maintenance of suicidal ideation, since suicidal patients often report difficulties in controlling suicidal thoughts and preventing them from repetitively entering their awareness. Germane to this, it has already been found that automatic self-injury associations were predictive of suicidal ideation during the past year, past suicide attempt, as well as future suicidal ideation, over and above known risk-factors (e.g., mood disorder, prior suicidal ideation, etc.; Nock and Banaji 2007).

Since depression is importantly being linked to suicidal ideation (e.g., Ellis 2006), the first goal of the present study was to test the hypothesis that automatic self-associations of depression relate to suicidal ideation. However, recent research also showed a link between anxiety disorders and suicidal ideation even after correcting for depressive symptoms (Norton et al. 2008). Therefore, the second goal of this study was to examine whether automatic self-associations of anxiety were related to suicidal ideation in addition to automatic self-depressive associations. Data were collected among a large sample of anxious and depressed patients and non-clinical controls as part of the Netherlands Study of Depression and Anxiety (see: www.nesda.nl). We used two adapted versions of the Implicit Association Test (IAT; Greenwald et al. 1998) to assess automatic self-depressive associations and automatic self-anxious associations. We hypothesized that both automatic self-depressive associations as well as automatic self-anxiety associations may relate significantly to suicidal ideation. If this indeed is the case, it could help explain the repetitive character of suicidal thoughts and the difficulty patients experience to control these thoughts.

\section{Methods}

The study was carried out in the context of the Netherlands Study of Depression and Anxiety (NESDA; Penninx et al. 2008), a multi-center, longitudinal, cohort study designed to examine the long-term course and consequences of anxiety and depressive disorders. This study concerns the baseline measurement that started in September 2004 and was completed in February 2007. The study protocol was approved centrally by the Ethical Review Board of the VU Medical Center Amsterdam and subsequently by the local review boards of each participating center/institute.

\section{Participants}

NESDA has been designed to be representative of those with depressive and anxiety disorders in different health care settings and stages of the developmental history. 
Therefore, recruitment of respondents took place in the general population, in general practices, and in mental health care institutions and included a range of psychopathology: those with no symptoms or disorders ('controls'), those with prior episodes or at risk because of sub threshold symptoms or family history, and those with a current first or recurrent depressive or anxiety disorder. Across recruitment setting, uniform in- and exclusion criteria were used. A general inclusion criterion was an age of 18 through 65 years. Only two exclusion criteria existed: 1) a primary clinical diagnosis of a psychiatric disorder not subject of NESDA which would largely affect course trajectory: psychotic disorder, obsessive compulsive disorder, bipolar disorder, or severe addiction disorder, and 2) not being fluent in Dutch since language problems would harm the validity and reliability of collected data. The focus of NESDA is on Dysthymia (current: $N=305$; life-time: $N=663)^{1}$, Major Depressive Disorder (MDD; current: $N=1,115$; lifetime: $N=1,925$ ), General Anxiety Disorder (current: $N=$ 464; life-time: $N=784$ ), Panic Disorder (current: $N=670$; life-time: $N=878$ ), Social Phobia (current: $N=665$; lifetime: $N=908$ ) and Agoraphobia (current: $N=187$; lifetime: $N=288)$. In total, 2,981 participants $(66.5 \%$ female; mean age $=41.9$ years, $\mathrm{SD}=13.0$ ) were included in the NESDA study of whom 652 were non-clinical controls without any depressive or anxiety disorder (for a more detailed description of the NESDA sample, see Penninx et al. 2008).

\section{Measurements}

\section{Implicit Association Test}

The IAT is a computerized reaction time task originally designed by Greenwald et al. (1998) to measure the relative strengths of automatic associations between two contrasted target concepts and two attribute concepts. Words from all four concept categories appear in mixed order in the middle of a computer screen and participants are instructed to sort them with a left $(\mathrm{Q})$ or right $(\mathrm{P})$ response key. The premise here is that the sorting becomes easier when a target and attribute that share the same response key are strongly associated than when they are weakly associated. The category labels are visible in the upper left and right-hand corners of the screen during the whole task (for an example see https://implicit.harvard.edu/implicit). Following the design of Egloff and Schmukle (2002), two IATs were

\footnotetext{
${ }^{1}$ The numbers between brackets refer to the number of diagnoses included in the NESDA. Current refers to the 6 months prevalence. The number of life-time diagnoses includes current as well as diagnoses earlier in life. Several participants had more than one current/life-time diagnosis.
}

constructed to measure automatic self-depressive associations and automatic self-anxious associations. For both IATs the target labels were me and other (other is seen as a generic contrast concept, Pinter and Greenwald 2005). The attribute labels were depressed and elated for the depression IAT and anxious and calm for the anxiety IAT. Each category consisted of five stimuli (see Appendix A). Both IATs consisted of two critical test blocks that were preceded by practice blocks (see Table 1). In one test block me and depressed/anxious (and other and elated/calm) shared the same response key, whereas in the other test block me and elated/calm (and other and depressed/anxious) shared the response key. Before the start of a new sorting task, written instructions were presented on screen. After a correct response, the next stimulus was presented after $500 \mathrm{~ms}$. Following an incorrect response, the Dutch word FOUT! (wrong) appeared shortly above the stimulus. Meanwhile, the stimulus remained on the screen until the correct response was given. The order of the category combinations was fixed across participants to reduce method variance. This is assumed to enhance the sensitivity of the IAT as a measure of individual differences, which is important in view of the prospective design of the NESDA (cf., Asendorpf et al. 2002; Schnabel et al. 2006; Steffens and König 2006).

To obtain explicit self-beliefs of depression and anxiety, participants rated all 20 IAT attribute stimuli on a 5-point scale (1=hardly/not at all, 5=very much) (i.e., "For each word please indicate to what extent you think it generally applies to you."). To compute the explicit self-beliefs, the mean ratings of the elated (calm) IAT-stimuli were subtracted from the mean ratings of the depressed (anxious) IAT-stimuli. Hence, a positive effect indicates

Table 1 Arrangement of the different IAT blocks

\begin{tabular}{llll}
\hline Block & Left Label(s) & Right Label(s) & No. of trials \\
\hline 1 Practice & me & other & 20 \\
2 Practice & anxious & calm & 20 \\
3 Practice & me / anxious & other / calm & 20 \\
4 Test & me / anxious & other / calm & 60 \\
5 Practice & calm & anxious & 20 \\
6 Practice & me / calm & other / anxious & 20 \\
7 Test & me / calm & other / anxious & 60 \\
8 Practice & depressed & elated & 20 \\
9 Practice & me / depressed & other / elated & 20 \\
10 Test & me / depressed & other / elated & 60 \\
11 Practice & elated & depressed & 20 \\
12 Practice & me / elated & other / depressed & 20 \\
13 Test & me / elated & other / depressed & 60 \\
\hline
\end{tabular}


a stronger explicit link between self and depressed/ anxious. The internal consistency of the explicit selfbeliefs was good, with Crohnbach's $\alpha$ 's for four subscales (anxious, calm, depressed, elated) varying from .89 to .91 .

\section{Suicidal Ideation}

Scale for Suicidal Ideation The Scale for Suicide Ideation (SSI; Beck et al. 1979) was used to measure suicidal ideation during the past week. The original scale contained 19 items, but item 6-19 are only asked when individuals score positive on the first items. Because the skewness of the SSI tends to be very high, it was decided only to include the first five items as part of the NESDA interview. Each item had three response categories (e.g. "Which feelings did you have during the past week concerning life and death? Did you want to live and how strong was this wish?" Scoring options: 0 -moderate to strong; 1-weak; 2-no wish). It appeared that the scores on the SSI were not normally distributed, because the majority of participants was nonsuicidal.

Item 18 of the Inventory of Depressive Symptoms SelfReport Version As a second measure of suicidal ideation during the past week, we used item 18 'Thoughts of death and suicide', which is part of the self-report Inventory of Depressive Symptoms (IDS-SR; Rush et al. 1996). This is a multiple-choice item existing of four response possibilities (0-“I don't think of suicide or death"; 1-“I have the feeling my life is empty and I wonder if it is still worth living for"; 2-"Several times a week I think of suicide or death"; 3-"Several times a day, I think seriously about suicide or death, or I made suicide plans, or I already made a suicide attempt"). Again the outcome was not normally distributed.

Because both measures of suicidal ideation were not normally distributed, it was not possible to use these measures as dependent variables in a normal regression analysis. Therefore, we decided to transform the outcomes of both measurements into one dichotomous variable where we grouped together the participants who scored above zero on both measures of suicidal ideation. Thus, participants who scored positive on one of the five items of the SSI and at the same time on item 18 of the IDS-SR were categorized as 'suicidal'. Participants scoring zero on both measures were categorized as 'non-suicidal'. Participants who had a missing value or that scored only positive on one of the measures were excluded from the analyses. Additionally, participants were asked if they had ever made a serious suicide attempt during their lives. This question was used as a dichotomous variable for past suicide attempt (yes/no).
Diagnostic Assessment

Depressive and anxiety disorders were determined by means of the lifetime Composite International Diagnostic Interview (CIDI) (WHO version 2.1, Robins et al. 1989), which classifies diagnoses according to the DSM-IV criteria (American Psychiatric Association 2001). In order to conduct the study, more than 40 research assistants (psychologists, nurses, and residents in psychiatry) were trained during one week by the fieldwork coordinator. All interviews were taped to monitor data quality and interviewer performance.

Procedure

The assessment lasted between three and five hours. During the assessment, first self-report questionnaires, the CIDI and Scale for Suicide Ideation were obtained, and then the IATs and explicit self-beliefs were administered. In between, other measurements were collected, but these are not of interest for the present study (for a detailed description, see Penninx et al. 2008). When the assessment was completed, respondents were compensated with a small incentive (a fifteen euro gift certificate and travel expenses) for their time and cooperation.

\section{Data Analyses}

\section{Data Reduction IAT}

IAT scores were computed according to the now widely used algorithm proposed by Greenwald et al. (2003). We report the $\mathrm{D}_{4}$-measure. Following these guidelines, all reaction times above $10,000 \mathrm{~ms}$ were discarded and error trials were replaced with the mean reaction times of the correct responses in the block in which the error occurred plus a penalty of $600 \mathrm{~ms}$. For the anxiety IAT, the IAT effect was calculated by subtracting the mean reaction times of Block 3 from Block 6 (practice) and Block 4 from Block 7 (test). The means of these two effects were divided by their pooled standard deviation based on all responses in Blocks 3, 4, 6 and 7. Analogously, the IAT effect was calculated for the depression IAT, based on Blocks 9, 10, 12 and 13.

Positive IAT effects indicate relatively fast responses when me shared the response key with either anxious or depressed. The split-half reliabilities of the present IATs was good, with Spearman-Brown corrected correlations between test-halves of .82 for the depression IAT and .87 for the anxiety IAT (test-halves were based on trials $1,2,5,6,9,10$ etc vs. $3,4,7,8,11,12$ etc.).

\section{Statistical Analyses}

The distributions of the measures for suicidal ideation were not normal, because non-suicidal individuals were overrep- 
Table 2 Means and standard deviations of variables and number of diagnoses during the past months for suicidal and non-suicidal participants
IAT Implicit Association Test, EA Explicit Associations,

** Difference between the two groups is significant at the 0.01 level (2-tailed), ${ }^{\text {a }} \%$ of the suicidal/non-suicidal group that has this diagnosis, Note that the percentages do not add up to 100 , because individuals often had more than 1 diagnosis

\begin{tabular}{|c|c|c|}
\hline Measure & Suicidal ideation $N=271$ & No suicidal ideation $N=1,950$ \\
\hline Gender, $\%$ female & 65.7 & 65.7 \\
\hline Age & $41.39(11.70)$ & $41.53(13.34)$ \\
\hline Educational level in years & $11.66(3.37)$ & $12.41(3.22)^{* *}$ \\
\hline IAT depression, D-measure & $-.02(.40)$ & $-.29(.38) * *$ \\
\hline IAT anxiety, D-measure & $-.07(.49)$ & $-.34(.50) * *$ \\
\hline EA depression & $.89(1.49)$ & $-1.93(1.33) * *$ \\
\hline EA anxiety & $1.14(1.35)$ & $-1.11(1.54) * *$ \\
\hline Suicide Attempt, \% yes & 29.5 & $6.3 * *$ \\
\hline Dysthymia & $89\left(32.8 \%{ }^{\mathrm{a}}\right)$ & $83\left(4.3 \%^{\mathrm{a}}\right) * *$ \\
\hline Major Depression & $198\left(73.1 \%^{\mathrm{a}}\right)$ & $287\left(14.7 \%{ }^{\mathrm{a}}\right) * *$ \\
\hline Social Phobia & $115\left(42.4 \%^{\mathrm{a}}\right)$ & $253\left(13.0 \%{ }^{\mathrm{a}}\right) * *$ \\
\hline Panic Disorder with Agoraphobia & $57\left(21 \%{ }^{a}\right)$ & $165\left(8.5 \%{ }^{a}\right) * *$ \\
\hline Panic Disorder without Agoraphobia & $31\left(11.4 \%^{\mathrm{a}}\right)$ & $72\left(3.7 \%{ }^{a}\right) * *$ \\
\hline Agoraphobia & $18\left(6.6 \%^{\mathrm{a}}\right)$ & $81\left(4.2 \%^{\mathrm{a}}\right)$ \\
\hline Generalized Anxiety Disorder & $96\left(35.4 \%^{\mathrm{a}}\right)$ & $161\left(8.3 \%{ }^{a}\right) * *$ \\
\hline None of the diagnoses above & $27\left(10.0 \%{ }^{\mathrm{a}}\right)$ & $1,278\left(65.5 \%{ }^{a}\right) * *$ \\
\hline
\end{tabular}

resented. Therefore, binary logistic regression was used to predict the dichotomous variables of suicidal ideation and past suicide attempt. Logistic regression follows the same general principle of linear regression; it is used when the outcome variable is a categorical dichotomy. Relations between the predictors and suicidal behavior are presented by means of odds ratios, which indicate the increased likelihood of suicidal behavior given an increase of one unit in the independent variable. The variables were standardized in order to make the odds ratios comparable. Furthermore, bivariate Spearman rank correlation coefficients were calculated between automatic and explicit self-depressive and selfanxious associations, suicidal ideation and suicide attempt. Additionally, although we were aware of the fact that the suicidal ideation and attempt variables were not continuous, partial correlations were reported to get a general idea of the shared variance between variables.
Our primary interest in the present paper was whether automatic self-associations of depression and anxiety relate to suicidal ideation. Therefore, hierarchic logistic regression analysis was performed with a theory-driven order of predictors. Since depression is importantly being linked to suicidal ideation, IAT depression was included in the first block. The second block consisted of IAT anxiety to examine whether automatic self-anxious associations added predictive value over and above automatic self-depressive associations. For the same reasons explicit self-depressive beliefs were added before explicit self-anxious beliefs in blocks 3 and 4 . To test whether the relationship between automatic self-depressive (anxiety) associations and suicidal thoughts would be especially strong in people also showing enhanced explicit self-depressive (anxiety) associations, the interaction between automatic self-depressive associations and explicit self-depressive beliefs was added in step 5 and the

Table 3 Correlation matrix of automatic and explicit self-anxious and self-depressive associations, suicidal ideation and attempt over all participants $(N=2,837)$

\begin{tabular}{|c|c|c|c|c|c|c|}
\hline Measure & 1. & 2. & 3. & 4. & 5. & 6. \\
\hline 1. IAT anxiety & - & $.49 * *$ & $.37 * *$ & $.32 * *$ & $.18^{* *}$ & $.11^{* *}$ \\
\hline 2. IAT depression & & - & $.35 * *$ & $.38 * *$ & $.22 * *$ & $.12 * *$ \\
\hline 3. EA anxiety & & & - & $.79 * *$ & $.40 * *$ & $.19 * *$ \\
\hline 4. EA depression & & & & - & $.47 * *$ & $.23 * *$ \\
\hline 5. Suicidal ideation ${ }^{a}$ & & & & & - & $.26^{* *}$ \\
\hline 6. Suicide attempt ${ }^{\mathrm{a}}$ & & & & & & - \\
\hline
\end{tabular}

IAT Implicit Association Test, EA Explicit Associations, ${ }^{* *}$ Correlation is significant at the 0.01 level (2-tailed), ${ }^{\text {a }}$ These are dichotomous variables, ' 0 ' stands for non-suicidal / no attempt and ' 1 ' stands for suicidal / attempt 
Table 4 Partial correlation matrix of automatic and explicit self-anxious and self-depressive associations with suicidal ideation $(N=2,221)$ and attempt $(N=2,820)$

\begin{tabular}{|c|c|c|c|c|c|}
\hline \multirow[t]{2}{*}{ Dependent Variable } & \multirow[t]{2}{*}{ Variable } & \multicolumn{4}{|c|}{ Variable corrected for } \\
\hline & & 1. IAT anxiety & 2. IAT depression & 3. EA anxiety & 4. EA depression \\
\hline \multirow[t]{4}{*}{ Suicidal ideation } & 1. IAT anxiety & - & $.08 * *$ & .03 & $-^{\mathrm{a}}$ \\
\hline & 2. IAT depression & $.16^{* *}$ & - & $-^{\mathrm{a}}$ & .02 \\
\hline & 3. EA anxiety & $.40 * *$ & $-^{\mathrm{a}}$ & - & -.01 \\
\hline & 4. EA depression & $--^{\mathrm{a}}$ & $.53 * *$ & $.40 * *$ & - \\
\hline \multirow[t]{4}{*}{ Suicide attempt } & 1. IAT anxiety & - & $.06^{* *}$ & $.04 *$ & $-^{\mathrm{a}}$ \\
\hline & 2. IAT depression & $.07 * *$ & - & $-^{\mathrm{a}}$ & .03 \\
\hline & 3. EA anxiety & $.17 * *$ & ${ }^{\mathrm{a}}$ & - & .02 \\
\hline & 4. EA depression & $-{ }^{\mathrm{a}}$ & $.21 * *$ & $.14^{* *}$ & - \\
\hline
\end{tabular}

IAT Implicit Association Test, EA Explicit Associations, **Correlation is significant at the 0.01 level (2-tailed), ${ }^{*}$ Correlation is significant at the 0.05 level (2-tailed), ${ }^{a}$ Only partial correlations were calculated correcting for the same emotion (depression or anxiety) or the same measurement method (IAT or EA)

same interaction for anxious self-associations was added in step 6. All tests were conducted with $\alpha<.05$.

\section{Results}

\section{Descriptives}

Due to technical problems, the IAT data and explicit selfbeliefs for 129 participants were missing. Furthermore, ten participants were discarded from all analyses because more than $10 \%$ of the IAT trials were below $300 \mathrm{~ms}$ (Greenwald et al. 2003), suggesting that they were trying to respond too rapidly. Five participants were discarded because of unusual D-scores ( $>5 \mathrm{SD}$ divergent from mean), that were explained by high error rates (>28.8\%). Additionally, 46 values were missing on the dichotomous measurement of suicidal ideation, because questionnaires were not returned, or because participants did not answer (1 on the Scale for Suicide Ideation; 45 on item 18 of the IDS-SR) and 570 participants were excluded from the analysis because they only scored positive on one of the two suicidal ideation measures. Finally, 17 values were missing on the measure of suicide attempt. Missing information on any of the variables resulted in exclusion of the case from the particular analysis. Both the scores on the SSI and item 18 of the IDS-SR were not normally distributed, because the majority of participants was non-suicidal (SSI: Skewness= 4.47, $\mathrm{SD}=.05$; Kurtosis $=22.53, \mathrm{SD}=.09$; item 18 IDS-SR: Skewness $=1.58, \mathrm{SD}=.05$; Kurtosis $=1.35, \mathrm{SD}=.09$ ). Consequently, one combined dichotomous measure of suicidal ideation was constructed, as is explained in the Method section. The descriptives of the variables as well as diagnoses of major depression and anxiety disorders during the past month for groups with and without suicidal ideation are reported in Table 2. The correlations between automatic and explicit self-depressive and self-anxious associations, suicidal ideation and attempt are shown in Table 3. Partial correlations of the predictors with suicidal ideation and attempt are shown in Table 4.

Are Automatic Self-Associations Predictive of Suicidal Ideation and Suicide Attempt?

Hierarchic logistic regression analysis showed that automatic self-depressive associations significantly predicted suicidal ideation (Table 5) and suicide attempt (Table 6). These odds ratios indicate an increased likelihood of suicidal ideation and past attempt, when people automatically associated themselves stronger with depressive words. Furthermore, the results consistently showed that automatic self-anxious associations predicted suicidal ideation and past suicide attempt over and above the automatic self-depressive associations. In both analyses, the effects of the IATs disappeared when explicit self-depressive beliefs were entered into the regression model. Only in the prediction of suicidal ideation, explicit self-anxious beliefs had predictive validity over and above explicit self-depressive beliefs. The interaction between automatic self-depressive associations and explicit self-depressive beliefs that was added in step 5 showed small, but differential predictive validity for both suicidal ideation and suicide attempt. Only in the prediction of suicidal ideation, the interaction between automatic selfanxious associations and explicit self-anxious beliefs added predictive validity on top of all other predictors. Together, this pattern of results indicates that individuals with depressive (anxious) explicit self-beliefs generally showed a greater probability of having suicidal thoughts than individuals with less depressive (anxious) self-beliefs, whereas this heightened probability of having suicidal thoughts was 
Table 5 Summary of logistic regression analysis for predicting suicidal ideation $(N=2,221)$
IAT Implicit Association Test, EA Explicit Associations, $O R$ Odds Ratio, $C I$ Confidence Interval, $* *$ Correlation is significant at the 0.01 level (2-tailed), *Correlation is significant at the 0.05 level (2-tailed)

\begin{tabular}{|c|c|c|c|c|}
\hline Variable & Wald & OR & $95 \% \mathrm{CI}$ & $\chi^{2}$ \\
\hline Step 1 & & & & $109.11 * *$ \\
\hline IAT depression & $104.08 * *$ & 1.95 & $1.72-2.22$ & \\
\hline Step 2 & & & & $12.16^{* *}$ \\
\hline IAT depression & $50.30 * *$ & 1.71 & $1.47-1.98$ & \\
\hline IAT anxiety & $12.11 * *$ & 1.30 & $1.12-1.51$ & \\
\hline Step 3 & & & & $538.63 * *$ \\
\hline IAT depression & 1.01 & 1.10 & $.92-1.32$ & \\
\hline IAT anxiety & .08 & 1.03 & $.85-1.23$ & \\
\hline EA depression & $329.52 * *$ & 6.16 & $.5 .06-7.50$ & \\
\hline Step 4 & & & & $6.15^{*}$ \\
\hline IAT depression & .99 & 1.10 & $.91-1.32$ & \\
\hline IAT anxiety & .02 & .99 & $.82-1.19$ & \\
\hline EA depression & $172.19^{* *}$ & 5.10 & $.4 .00-6.50$ & \\
\hline EA anxiety & $6.17 *$ & 1.37 & $1.07-1.77$ & \\
\hline Step 5 & & & & $4.05^{*}$ \\
\hline IAT depression & $4.63 *$ & 1.35 & $1.03-1.76$ & \\
\hline IAT anxiety & .01 & .99 & $.82-1.19$ & \\
\hline EA depression & $166.36^{* *}$ & 5.53 & $4.27-7.18$ & \\
\hline EA anxiety & $5.52 *$ & 1.35 & $1.05-1.74$ & \\
\hline Int IATdep x EA dep & $4.14 *$ & .75 & $.57-.99$ & \\
\hline Step 6 & & & & $5.40 *$ \\
\hline IAT depression & 2.25 & 1.24 & $.94-1.64$ & \\
\hline IAT anxiety & 2.55 & 1.25 & $.95-1.63$ & \\
\hline EA depression & $158.36^{* *}$ & 5.32 & $4.10-6.90$ & \\
\hline EA anxiety & $8.26^{* *}$ & 1.47 & $1.13-1.92$ & \\
\hline Int IATdep x EA dep & 1.31 & .84 & $.62-1.13$ & \\
\hline Int IATanx $x$ EA anx & $5.36^{*}$ & .77 & $.62-.96$ & \\
\hline
\end{tabular}

increased further for individuals who had also depressive (anxious) self-associations on a more automatic level. ${ }^{2}$

\section{Discussion}

The present study was designed as a first step in getting more insight into the relationship between suicidal ideation and automatic self-associations of depression and anxiety. In line with what we expected, the results showed that automatic self-depressive associations were significantly related to suicidal ideation and past suicide attempt. Furthermore, automatic self-anxious associations showed predictive validity for suicidal ideation/attempt in addition to the automatic self-depressive associations. Although the main-effects of automatic self-associations did not explain

\footnotetext{
${ }^{2}$ We repeated the analyses in a subgroup of participants that did not use a benzodiazepine at present to see whether use of medication would influence the results. In general, the patterns of results were the same, except for the interaction effects that were no longer significant. However, this can also be the result of less power due to the smaller group sizes.
}

additional variance over and above explicit self-beliefs, the interactions between automatic self-depressive (anxious) associations and explicit self-depressive (anxious) beliefs did.

It is an important, new observation that traces of dysfunctional self-schemas can be found in suicidal individuals both on an explicit, reflective level, and on a more automatic level (see e.g., Gawronski and Bodenhausen 2006). The fact that automatic self-anxious associations even showed predictive validity for suicidal ideation/attempt in addition to automatic self-depressive associations is particularly new and in accordance with recent studies showing a relationship between anxiety disorder symptoms and suicidality (Norton et al. 2008; Sareen et al. 2005). Furthermore, the relationship between automatic self-depressive (anxious) associations and suicidal thoughts appeared especially strong in people also showing enhanced explicit self-depressive (anxious) associations. In other words, the probability of having suicidal thoughts was especially high for individuals who had depressive (anxious) self-associations both on an automatic level and an explicit level. Perhaps individuals with relatively positive explicit beliefs about themselves 
Table 6 Summary of logistic regression analysis for predicting suicide attempt $(N=2,820)$

\begin{tabular}{|c|c|c|c|c|}
\hline Variable & Wald & OR & $95 \% \mathrm{CI}$ & $\chi^{2}$ \\
\hline Step 1 & & & & $38.82 * *$ \\
\hline IAT depression & $38.89 * *$ & 1.44 & $1.28-1.61$ & \\
\hline Step 2 & & & & $10.35^{* *}$ \\
\hline IAT depression & $14.32 * *$ & 1.29 & $1.13-1.47$ & \\
\hline IAT anxiety & $10.38 * *$ & 1.24 & $1.09-1.42$ & \\
\hline Step 3 & & & & $104.75^{* *}$ \\
\hline IAT depression & .58 & 1.06 & $.92-1.21$ & \\
\hline IAT anxiety & 2.70 & 1.12 & $.98-1.28$ & \\
\hline EA depression & $103.02 * *$ & 1.88 & $1.67-2.13$ & \\
\hline Step 4 & & & & .92 \\
\hline IAT depression & .63 & 1.06 & $.92-1.21$ & \\
\hline IAT anxiety & 1.95 & 1.10 & $.96-1.27$ & \\
\hline EA depression & $39.46^{* *}$ & 1.77 & $1.48-2.11$ & \\
\hline EA anxiety & .92 & 1.10 & $.91-1.33$ & \\
\hline Step 5 & & & & $4.46^{*}$ \\
\hline IAT depression & 2.74 & 1.14 & $.98-1.33$ & \\
\hline IAT anxiety & 2.18 & 1.11 & $.97-1.28$ & \\
\hline EA depression & $44.12 * *$ & 1.85 & $1.54-2.22$ & \\
\hline EA anxiety & .55 & 1.08 & $.89-1.30$ & \\
\hline Int IATdep x EA dep & $4.37^{*}$ & .84 & $.71-.99$ & \\
\hline Step 6 & & & & .79 \\
\hline IAT depression & 2.14 & 1.12 & $.96-1.32$ & \\
\hline IAT anxiety & 2.95 & 1.15 & $.98-1.34$ & \\
\hline EA depression & $42.50 * *$ & 1.83 & $1.53-2.20$ & \\
\hline EA anxiety & .79 & 1.09 & $.90-1.32$ & \\
\hline Int IATdep x EA dep & 2.42 & .87 & $.72-.104$ & \\
\hline Int IATanx $x$ EA anx & .79 & .94 & $.81-1.09$ & \\
\hline
\end{tabular}

IAT Implicit Association Test, EA Explicit Associations, OR Odds Ratio, $C I$ Confidence Interval, ${ }^{*}$ Correlation is significant at the 0.01 level (2-tailed)

(e.g., "I am elated" or "I am calm") are better able and/or stronger motivated to neutralize or correct the influence of automatic negative self-associations (e.g., self-depressive or self-anxious) than individuals with more negative explicit self-evaluations (cf. de Jong et al. 2003). In other words, in individuals with negative self-associations on both automatic and explicit levels this correction might not take place thereby enhancing the risk of eliciting suicidal ideation.

Although the interactions of automatic self-depressive (anxious) associations with explicit self-depressive (anxious) beliefs had only small additional predictive validity and automatic self-associations per se did not uniquely contribute to the prediction of suicidal ideation or attempt over and above their explicit counterparts, this does not imply that automatic self-associations are therefore largely redundant. For the understanding of suicidal ideation, it seems crucial to gain insight into the underlying cognitive structures that are relatively unconscious, especially because suicidal patients often report difficulties in controlling suicidal thoughts and rapid and unconscious changes in their thinking about suicide. Furthermore, according to recently developed informationprocessing models (e.g., Fazio and Towles-Schwen 1999; Wilson et al. 2000), automatic and explicit cognitions are assumed to predict different kind of behaviors. Explicit associations (beliefs) tend to predict more deliberate, controlled behaviors, whereas automatic associations are most critical for guiding relatively spontaneous behaviors (Asendorpf et al. 2002; Egloff and Schmukle 2002; Huijding and de Jong 2006). There is evidence that this is especially important in circumstances where there is little cognitive capacity left to deliberate about these automatic associations. Accordingly, recent research in the context of alcohol abuse showed that working memory moderates the influence of automatic associations on drinking behavior (Thush et al. 2008). Only in adolescents with a relatively small working memory capacity, automatic alcohol associations were predictive of drinking behavior. Analogously, cognitive capacity could also play a role in the context of suicidal ideation. When cognitive capacity is limited, for example by natural ability or by other factors such as life-stress, dysfunctional automatic self-associations might obtain a stronger influence (Beevers 2005). In these cases, the automatic activation of dysfunctional self-associations could function as a repeating trigger for repetitive negative thoughts of suicide or death, even when more positive beliefs might exist on an explicit level.

In the present study the focus was on automatic selfassociations of depression and anxiety. Therefore, it can not be ruled out that other automatic self-associations may still be independently related to suicidal ideation. Moreover, it should be acknowledged, that the present approach may have resulted in an underestimation of the importance of automatic selfassociations in the context of suicidal behavior. That is, in the present study the relationship between explicit self-beliefs and suicidal ideation may have been artificially increased because there was methodological overlap between these measures (both were self-report measures). However, the present strong association between suicidal ideation and explicit negative self-beliefs is consistent with earlier findings (e.g., Beck and Steward 1989, cited in Weishaar and Beck 1992; De Man and Gutiérrez 2002; Evans et al. 2004) and seems to underline once more the importance of dysfunctional self-schemas for suicidal ideation.

In conclusion, the present study clearly showed that automatic self-associations are related to suicidal thoughts, which is in line with clinical experience and the theoretical starting point that suicidal thoughts stem from dysfunctional schemas in memory. The finding that this does not only concern automatic self-depressive associations, but that also automatic self-anxious associations are related to suicidal 
ideation, is especially new. Although automatic selfassociations per se did not explain additional variance over and above explicit self-beliefs, the interaction between automatic and explicit self-associations did. This suggests that the probability of having suicidal thoughts was especially high for individuals who had depressive (anxious) selfassociations on both an automatic and an explicit level. Future research has to affirm whether this indeed is a robust finding that needs further investigation. Furthermore, it would be important to see whether automatic self-associations have perhaps prognostic value for the course of suicidal ideation and to test whether the predictive validity of automatic associations for suicidal ideation is moderated by cognitive capacity. Together, these results provide an initial insight into the more unconscious parts of cognitive structures that underlie suicidal ideation, which is one plausible explanation of why suicidal patients might report difficulties in preventing and managing suicidal thoughts.

Acknowledgments The infrastructure for the NESDA study (www. nesda.nl) is funded through the Geestkracht program of the Netherlands Organisation for Health Research and Development (Zon-Mw, grant number 10-000-1002) and is supported by participating universities and mental health care organizations [VU University Medical Center, GGZ inGeest, Arkin, Leiden University Medical Center, GGZ Rivierduinen, University Medical Center Groningen, Lentis, GGZ Friesland, GGZ Drenthe, Scientific Institute for Quality of Healthcare (IQ healthcare), Netherlands Institute for Health Services Research (NIVEL) and Netherlands Institute of Mental Health and Addiction (Trimbos)]. We thank Bert Hoekzema for technical support; PSY-opleidingen Noord Oost for financial support of the first author.

Open Access This article is distributed under the terms of the Creative Commons Attribution Noncommercial License which permits any noncommercial use, distribution, and reproduction in any medium, provided the original author(s) and source are credited.

\section{Appendix A}

\section{IAT Stimulus Words}

Me: I, myself, self, my, own

Other: other, you, they, them, themselves

Depressed: useless, pessimistic, inadequate, negative, meaningless

Elated: positive, optimistic, active, valuable, cheerful Anxious: anxious, afraid, nervous, insecure, worried

Calm: calm, balanced, placid, secure, relaxed

Note. Words are translated from Dutch

\section{References}

American Psychiatric Association. (2001). Diagnostic and statistical manual of mental disorders (Vol. 4). Washington, DC: American Psychiatric Association. text revision.
Asendorpf, J. B., Banse, R., \& Mücke, D. (2002). Double dissociation between implicit and explicit personality self-concept: the case of shy behavior. Journal of Personality and Social Psychology, 83, 380-393.

Beck, A. T., Kovacs, M., \& Weissman, A. (1979). Assessment of suicidal intention: the scale for suicide ideation. Journal of Consulting and Clinical Psychology, 47, 343-352.

Becker, D. F., \& Grilo, C. M. (2007). Prediction of suicidality and violence in hospitalized adolescents: comparisons by sex. The Canadian Journal of Psychiatry/La Revue canadienne de psychiatrie, 52, 572-580.

Beevers, C. G. (2005). Cognitive vulnerability to depression: a dual process model. Clinical Psychology Review, 25, 975-1002.

Clark, D. A., Beck, A. T., \& Alford, B. A. (1999). Scientific foundations of cognitive theory and therapy of depression. Hoboken: Wiley.

Cox, B. J., Enns, M. W., \& Clara, I. P. (2004). Psychological dimensions associated with suicidal ideation and attempts in the National Comorbidity Survey. Suicide and Life-Threatening Behavior, 34, 209-219.

De Houwer, J. (2002). The implicit association test as a tool for studying dysfunctional associations in psychopathology: strengths and limitations. Journal of Behavior Therapy and Experimental Psychiatry, 33, 115-133.

de Jong, P. J., van den Hout, M. A., Rietbroek, H., \& Huijding, J. (2003). Dissociations between implicit and explicit attitudes toward phobic stimuli. Cognition \& Emotion, 17, 521-545.

De Man, A. F., \& Gutiérrez, B. I. B. (2002). The relationship between level of self-esteem and suicidal ideation with stability of selfesteem as moderator. Canadian Journal of Behavioural Science/ Revue canadienne des Sciences du comportement, 34, 235-238.

Egloff, B., \& Schmukle, S. C. (2002). Predictive validity of an implicit association test for assessing anxiety. Journal of Personality and Social Psychology, 83, 1441-1455.

Ellis, T. E. (2006). Cognition and suicide: Theory, research, and therapy. Washington, DC: American Psychological Association.

Evans, E., Hawton, K., \& Rodham, K. (2004). Factors associated with suicidal phenomena in adolescents: a systematic review of population-based studies. Clinical Psychology Review, 24, 957-979.

Fazio, R. H., \& Towles-Schwen, T. (1999). The MODE model of attitude-behavior processes. New York: Guilford.

Gamer, J., Schmukle, S. C., Luka-Krausgrill, U., \& Egloff, B. (2008). Examining the dynamics of the implicit and the explicit selfconcept in social anxiety: changes in the implicit association testanxiety and the social phobia anxiety inventory following treatment. Journal of Personality Assessment, 90(5), 476-480.

Gawronski, B., \& Bodenhausen, G. V. (2006). Associative and propositional processes in evaluation: an integrative review of implicit and explicit attitude change. Psychological Bulletin, 132, 692-731.

Glashouwer, K. A., \& de Jong, P. J. (in press). Disorder-specific automatic self-associations in depression and anxiety. Results of the Netherlands Study of Depression and Anxiety. Psychological Medicine.

Greenwald, A. G., \& Farnham, S. D. (2000). Using the implicit association test to measure self-esteem and self-concept. Journal of Personality and Social Psychology, 79, 1022-1038.

Greenwald, A. G., McGhee, D. E., \& Schwartz, J. L. K. (1998). Measuring individual differences in implicit cognition: the implicit association test. Journal of Personality and Social Psychology, 74, 1464-1480.

Greenwald, A. G., Nosek, B. A., \& Banaji, M. R. (2003). Understanding and using the Implicit Association Test: I. An improved scoring algorithm. Journal of Personality and Social Psychology, 85, 197-216.

Grumm, M., Erbe, C., von Collani, G., \& Nestler, S. (2008). Automatic processing of pain: the change of implicit pain 
associations after psychotherapy. Behaviour Research and Therapy, 46, 701-714.

Huijding, J., \& de Jong, P. J. (2006). Specific predictive power of automatic spider-related affective associations for controllable and uncontrollable fear responses toward spiders. Behaviour Research and Therapy, 44, 161-176.

Kessler, R. C., Borges, G., \& Walters, E. E. (1999). Prevalence of and risk factors for lifetime suicide attempts in the National Comorbidity Survey. Archives of General Psychiatry, 56, 617-626.

Kienhorst, C. W., de Wilde, E. J., Van den Bout, J., \& Diekstra, R. F. (1990). Characteristics of suicide attempters in a populationbased sample of Dutch adolescents. British Journal of Psychiatry, 156, 243-248.

Lewinsohn, P. M., Rohde, P., \& Seeley, J. R. (1994). Psychosocial risk factors for future adolescent suicide attempts. Journal of Consulting and Clinical Psychology, 62, 297-305.

Nock, M. K., \& Banaji, M. R. (2007). Prediction of suicide ideation and attempts among adolescents using a brief performance-based test. Journal of Consulting and Clinical Psychology, 75, 707715 .

Norton, P. J., Temple, S. R., \& Pettit, J. W. (2008). Suicidal ideation and anxiety disorders: elevated risk or artifact of comorbid disorder? Journal of Behavior Therapy and Experimental Psychiatry, 39, 515-525.

Penninx, B. W. J. H., Beekman, A. T. F., Smit, J. H., Zitman, F. G., Nolen, W. A., Spinhoven, P., et al. (2008). The Netherlands Study of Depression and Anxiety (NESDA): rationale, objectives and methods. International Journal of Methods in Psychiatric Research, 17, 121-140.

Pinter, B., \& Greenwald, A. G. (2005). Clarifying the role of the 'other' category in the self-esteem IAT. Experimental Psychology, $52,74-79$.

Robins, L. N., Wing, J., Wittchen, H. U., Helzer, J. E., Babor, T. F., Burke, J., et al. (1989). The composite international diagnostic interview: an epidemiologic instrument suitable for use in conjunction with different diagnostic systems and in different cultures. Archives of General Psychiatry, 45, 1069-1077.

Rush, A. J., Gullion, C. M., Basco, M. R., \& Jarrett, R. B. (1996). The inventory of depressive symptomatology (IDS): psychometric properties. Psychological Medicine, 26, 477-486.

Sareen, J., Cox, B. J., Afifi, T. O., de Graaf, R., Asmundson, G. J. G., ten Have, M., et al. (2005). Anxiety disorders and risk for suicidal ideation and suicide attempts: a population-based longitudinal study of adults. Archives of General Psychiatry, 62, 1249-1257.

Schnabel, K., Banse, R., \& Asendorpf, J. B. (2006). Assessment of implicit personality self-concept using the Implicit Association Test (IAT): concurrent assessment of anxiousness and angriness. British Journal of Social Psychology, 45, 373-396.

Steffens, M. C., \& König, S. S. (2006). Predicting spontaneous Big Five behavior with implicit association tests. European Journal of Psychological Assessment, 22, 13-20.

Thush, C., Wiers, R. W., Ames, S. L., Grenard, J. L., Sussman, S., \& Stacy, A. W. (2008). Interactions between implicit and explicit cognition and working memory capacity in the prediction of alcohol use in at-risk adolescents. Drug and Alcohol Dependence, 94, 116-124.

Weertman, A., Arntz, A., de Jong, P. J., \& Rinck, M. (2008). Implicit self- and other-associations in obsessive-compulsive personality disorder traits. Cognition and Emotion, 22, 1253-1275.

Weishaar, M. A., \& Beck, A. T. (1992). Clinical and cognitive predictors of suicide. In R. W. Maris, A. L. Berman, J. T. Maltsberger \& R. I. Yufit (Eds.), Assessment and prediction of suicide (pp. 467-438). New York: Guilford.

Wilson, T. D., Lindsey, S., \& Schooler, T. Y. (2000). A model of dual attitudes. Psychological Review, 107, 101-126.

World Health Organization. (2003). World health report 2003: Shaping the future. Geneva: World Health Organization.

Young, J. E. (1990). Cognitive therapy for personality disorders: A schema-focused approach. England: Professional Resource Exchange, Inc. 